\title{
Impact of ageing and pregnancy on the minute ventilation/ carbon dioxide production response to exercise
}

\author{
Michele R. Schaeffer ${ }^{1,2}$, Jordan A. Guenette ${ }^{1,2,3}$ and Dennis Jensen ${ }^{4,5,6}$
}

\author{
Number 6 in the Series "Ventilatory efficiency and its clinical prognostic value in cardiorespiratory \\ disorders" \\ Edited by Pierantonio Laveneziana and Paolo Palange
}

\begin{abstract}
${ }^{1}$ Centre for Heart Lung Innovation, Providence Health Care Research Institute, The University of British Columbia, St. Paul's Hospital, Vancouver, Canada. ${ }^{2}$ Dept of Physical Therapy, The University of British Columbia, Vancouver, Canada. ${ }^{3}$ School of Kinesiology, The University of British Columbia, Vancouver, Canada. ${ }^{4}$ Dept of Kinesiology and Physical Education, McGill University, Montréal, Canada. ${ }^{5}$ Research Institute of the McGill University Health Centre, Translational Research in Respiratory Diseases Program, Montréal, Canada. ${ }^{6}$ Research Centre for Physical Activity and Health, Faculty of Education, McGill University, Montréal, Canada.
\end{abstract}

Corresponding author: Jordan A. Guenette (jordan.guenette@hli.ubc.ca)

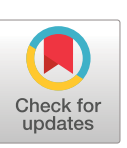

Copyright @ERS 2021

This article is open access and distributed under the terms of the Creative Commons Attribution Non-Commercial Licence 4.0.

Received: 10 July 2020 Accepted: 27 Sept 2020

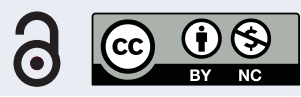

Shareable abstract (@ERSpublications)

The minute ventilation/carbon dioxide production response to exercise is elevated with advancing age and in healthy pregnancy due to increased dead space and lowering of the arterial partial pressure of carbon dioxide equilibrium point, respectively. https://bit.ly/2GJXm0o

Cite this article as: Schaeffer MR, Guenette JA, Jensen D. Impact of ageing and pregnancy on the minute ventilation/carbon dioxide production response to exercise. Eur Respir Rev 2021; 30: 200225 [DOI: 10.1183/16000617.0225-2020].

Abstract

Ventilatory efficiency can be evaluated using the relationship between minute ventilation $\left(V_{\mathrm{E}}^{\prime}\right)$ and the rate of $\mathrm{CO}_{2}$ production $\left(V^{\prime} \mathrm{CO}_{2}\right)$. In accordance with the modified alveolar ventilation equation, this relationship is determined by changes in dead space volume $\left(V_{\mathrm{D}}\right)$ and/or the arterial $\mathrm{CO}_{2}$ tension $\left(P_{\mathrm{aCO}}\right)$ equilibrium point. In this review, we summarise the physiological factors that may account for normative ageing and pregnancy induced increases in $V_{E}^{\prime} / V^{\prime} \mathrm{CO}_{2}$ during exercise. Evidence suggests that age-related increases in $V_{\mathrm{D}}$ and pregnancy-related decreases in the $P_{\mathrm{aCO}}$ equilibrium point are mechanistically linked to the increased $V^{\prime}{ }_{\mathrm{E}} / V^{\prime} \mathrm{CO}_{2}$ during exercise. Importantly, the resultant increase in $V_{\mathrm{E}}^{\prime} / V^{\prime} \mathrm{CO}_{2}$ (ratio or slope), with normal ageing or pregnancy, remains below the critical threshold for prognostic indication in cardiopulmonary disease, is not associated with increased risk of adverse health outcomes, and does not affect the respiratory system's ability to fulfil its primary role of eliminating $\mathrm{CO}_{2}$ and maintaining arterial oxygen saturation during exercise.

\section{Introduction}

The ventilatory response to exercise is well coordinated and matched to the rate of $\mathrm{CO}_{2}$ production $\left(V^{\prime} \mathrm{CO}_{2}\right)$. The strength of the relationship between minute ventilation $\left(V_{\mathrm{E}}^{\prime}\right)$ and $V_{\mathrm{CO}_{2}}^{\prime}$ is marked by relative homeostasis of the arterial $\mathrm{CO}_{2}$ tension $\left(\mathrm{P}_{\mathrm{aCO}_{2}}\right)$ even in the context of the large increases in $V^{\prime} \mathrm{CO}_{2}$ that occur during exercise [1]. Ventilatory efficiency can be evaluated using this relationship, whereby an increase in $V^{\prime}{ }_{E} / V^{\prime} \mathrm{CO}_{2}$ has been suggested to indicate less efficiency [2].

As summarised by the modified alveolar ventilation equation: $V_{\mathrm{E}}^{\prime}=\left(V_{\mathrm{CO}_{2}}^{\prime} \times 863\right) /\left(P_{\mathrm{aCO}} \times\left(1-V_{\mathrm{D}} / V_{\mathrm{T}}\right)\right.$ ) (figure 1$)$, $V_{\mathrm{E}}^{\prime} / V_{\mathrm{CO}_{2}}^{\prime}$ is dependent on both the $P_{\mathrm{aCO}_{2}}$ equilibrium point and the fraction of dead space, which is expressed as the ratio of dead space volume to tidal volume $\left(V_{\mathrm{D}} / V_{\mathrm{T}}\right)$. According to established models of ventilatory control [3-5], resting steady-state $V_{\mathrm{E}}^{\prime}$ and $P_{\mathrm{aCO}}$ are determined by chemoreflex (central and peripheral) and non-chemoreflex ("wakefulness") drives to breathe and their intersection with the metabolic hyperbola (figure 2), which represents the curvilinear relation between $V_{\mathrm{E}}^{\prime}$ and $P_{\mathrm{aCO}}$ at any given $V_{\mathrm{CO}_{2}}^{\prime}$ and $V_{\mathrm{D}} / V_{\mathrm{T}}$. This point of intersection, often referred to as the respiratory control system's $P_{\mathrm{aCO}}$ equilibrium point, is inversely 


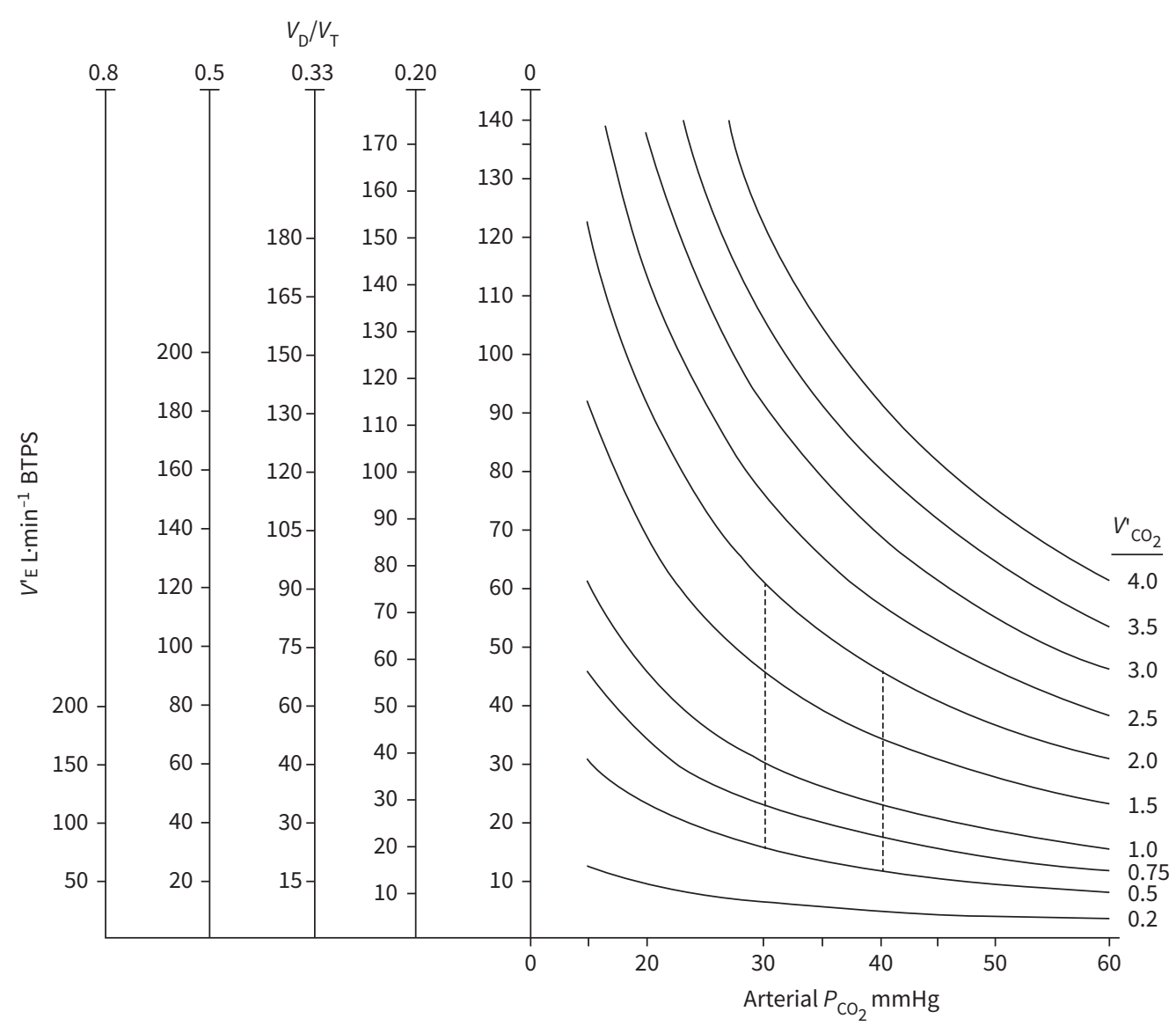

FIGURE 1 Minute ventilation $\left(V_{E}^{\prime}\right)$ required for various rates of metabolic production of carbon dioxide production $\left(\mathrm{V}^{\prime} \mathrm{CO}_{2}\right)$ as modified by the carbon dioxide tension $\left(\mathrm{P}_{\mathrm{CO}_{2}}\right)$ in the arterial blood and the physiological dead space volume to tidal volume ratio $\left(V_{\mathrm{D}} / V_{\mathrm{T}}\right)$. Adapted and modified from [82] with permission from the publisher.

related to the $V_{\mathrm{E}}^{\prime} / V^{\prime} \mathrm{CO}_{2}$ response to exercise at a constant $V_{\mathrm{D}} / V_{\mathrm{T}}$. For example, at a $V_{\mathrm{D}} / V_{\mathrm{T}}$ of 0.20 , a decrease in the respiratory control system's $P_{\mathrm{aCO}_{2}}$ equilibrium point from $40 \mathrm{mmHg}$ to $32 \mathrm{mmHg}$ would increase $V_{\mathrm{E}}^{\prime}$ from $\sim 40$ to $\sim 50 \mathrm{~L} \cdot \mathrm{min}^{-1}$ at a $V_{\mathrm{CO}_{2}}^{\prime}$ of $1.5 \mathrm{~L} \cdot \mathrm{min}^{-1}$, which corresponds to moderate intensity exercise (figure 1). Accordingly, a lowering of the $P_{\mathrm{aCO}_{2}}$ equilibrium point, such as occurs during pregnancy, results in a higher $V_{\mathrm{E}}^{\prime} / V^{\prime} \mathrm{CO}_{2}$ (e.g. at any given $V_{\mathrm{D}} / V_{\mathrm{T}}, V_{\mathrm{E}}^{\prime} / V^{\prime} \mathrm{CO}_{2}$ will increase as $P_{\mathrm{aCO}_{2}}$ decreases), while an increase in relative $V_{\mathrm{D}} / V_{\mathrm{T}}$, such as occurs with normative ageing, results in a higher $V_{\mathrm{E}}^{\prime} / V_{\mathrm{CO}_{2}}^{\prime}$ (e.g. at any given $P_{\mathrm{aCO}_{2}}, V_{\mathrm{E}}^{\prime} / V_{\mathrm{CO}_{2}}^{\prime}$ will increase as $V_{\mathrm{D}} / V_{\mathrm{T}}$ increases).

The three most common ways of assessing exercise ventilatory efficiency are: 1) using the $V_{\mathrm{E}}^{\prime} / V^{\prime} \mathrm{CO}_{2}$ slope (i.e. $\left.\Delta V_{\mathrm{E}}^{\prime} / \Delta V_{\mathrm{CO}_{2}}^{\prime}\right)$ in the aerobic working range; 2) the value of $V^{\prime}{ }_{\mathrm{E}} / V^{\prime} \mathrm{CO}_{2}$ at the anaerobic threshold $\left(V^{\prime}{ }_{\mathrm{E}} /\right.$ $V^{\prime} \mathrm{CO}_{2} \mathrm{AT}$ ); and/or 3) the $V^{\prime}{ }_{\mathrm{E}} / V^{\prime} \mathrm{CO}_{2}$ nadir, which represents the lowest $V^{\prime}{ }_{\mathrm{E}} / V^{\prime} \mathrm{CO}_{2}$ during exercise. While the $V^{\prime} / V^{\prime} \mathrm{CO}_{2}$ nadir has been shown to be the most reproducible index of exercise ventilatory efficiency, it is nearly identical to $V^{\prime}{ }_{E} / V^{\prime} \mathrm{CO}_{2} \mathrm{AT}$ for a given age and sex, and both are slightly higher than the $V_{\mathrm{E}}^{\prime} / V^{\prime} \mathrm{CO}_{2}$ slope [6]. A $V_{E}^{\prime} / V_{\mathrm{CO}_{2}}^{\prime}$ slope during exercise between 21-31 [6] and a $V_{\mathrm{E}}^{\prime} / V_{\mathrm{CO}_{2}}^{\prime}\left(V_{\mathrm{E}}^{\prime} / V^{\prime} \mathrm{CO}_{2} \mathrm{AT}\right.$ or nadir) $<34$ [7] are considered normal. Of note, use of the $V^{\prime}{ }_{E} / V^{\prime}{ }_{\mathrm{CO}_{2}}$ slope alone should be made with caution as it does not provide information on the orientation of this relationship relative to the $V_{\mathrm{E}}^{\prime}$ axis [8]. Proper evaluation using this approach should also include the $V_{\mathrm{E}}^{\prime}$ intercept. An additional methodological consideration is the subtraction of instrument dead space (e.g. mouthpiece, adapters, flow transducer, etc.) multiplied by the breathing frequency from the measured $V_{\mathrm{E}}^{\prime}$, which, when unaccounted for, has been shown to artificially inflate both the $V^{\prime}{ }_{\mathrm{E}} / V^{\prime} \mathrm{CO}_{2}$ slope and intercept [6].

The assessment of $V^{\prime}{ }_{\mathrm{E}} / V^{\prime} \mathrm{CO}_{2}$ during cardiopulmonary exercise testing can distinguish pathologies as well as elucidate mechanisms of exertional dyspnoea [9]. With less ventilatory efficiency, mechanical ventilatory constraints may be attained at a lower $V^{\prime}$, and neural respiratory neural drive may be increased, both of 


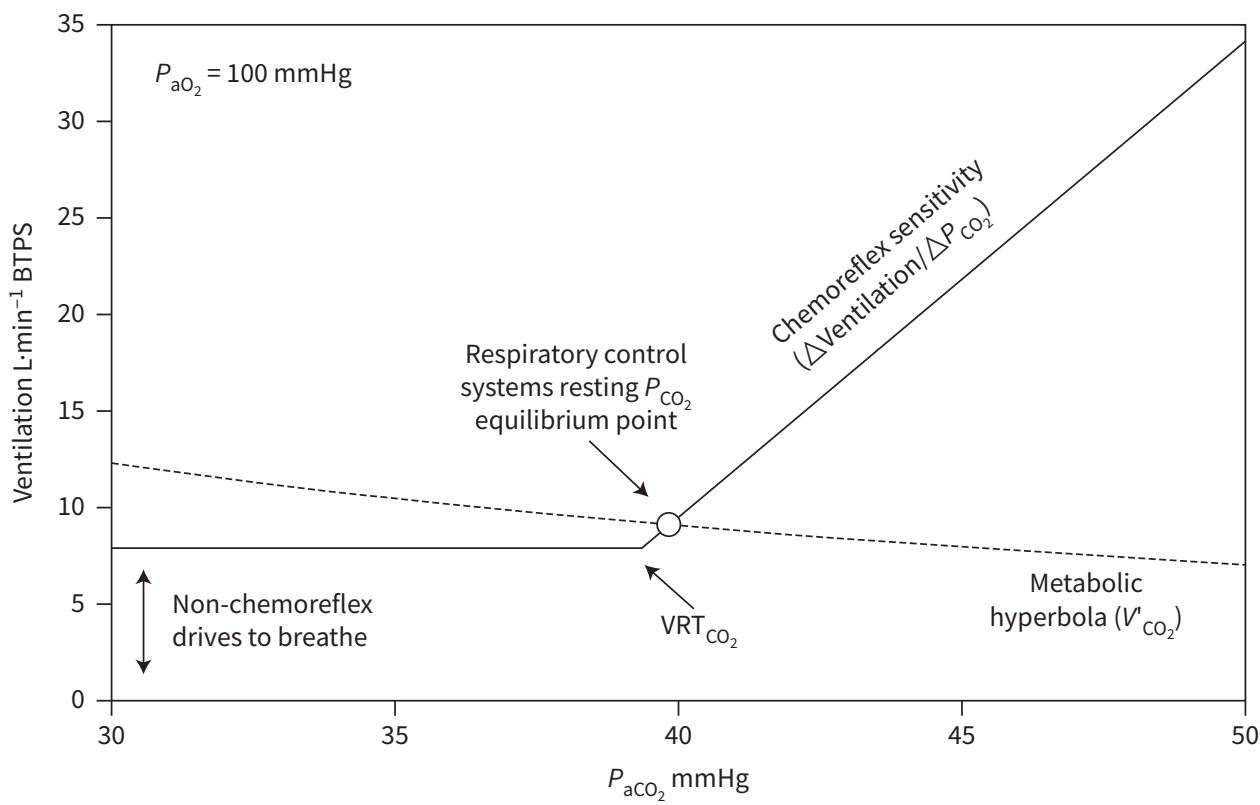

FIGURE 2 Graphical representation of the physiological determinants of the respiratory control systems' resting arterial carbon dioxide tension $\left(P_{\mathrm{acO}}\right)$ equilibrium point. Briefly, resting steady-state minute ventilation $\left(V^{\prime} \mathrm{E}\right)$ and $P_{\mathrm{aCO}}$ depend on chemoreflex as well as "other" non-chemoreflex (wakefulness) drives to breathe and their intersection with the metabolic hyperbola, which represents the curvilinear relation between $V^{\prime}$ and $P_{\mathrm{acO}}$ at a constant rate of $\mathrm{CO}_{2}$ production $\left(V^{\prime} \mathrm{CO}_{2}\right)$ and fraction of dead space to tidal volume ratio $\left(V_{\mathrm{D}} / V_{\mathrm{T}}\right)$, as defined by the modified alveolar ventilation equation: $V_{\mathrm{E}}^{\prime}=\left(V_{\mathrm{CO}_{2}}^{\prime} \times 863\right) /\left(P_{\mathrm{aCO}} \times\left(1-\left(V_{\mathrm{D}} / V_{\mathrm{T}}\right)\right)\right) . P_{\mathrm{aO}_{2}}$ : arterial $P_{\mathrm{O}_{2}} ; \mathrm{VRT}_{\mathrm{CO}_{2}}$ : ventilatory recruitment threshold for $\mathrm{CO}_{2} ; P_{\mathrm{aO}}$ : arterial oxygen tension; $P_{\mathrm{acO}}$ : carbon dioxide tension; $\triangle$ : change. Reproduced from [52] with permission from the publisher.

which can contribute to dyspnoea and exercise intolerance. For example, an elevated $V_{E}^{\prime} / V^{\prime} \mathrm{CO}_{2}$ in the context of a preserved $P_{\mathrm{aCO}_{2}}$ equilibrium point suggests high dead space ventilation $\left(V_{\mathrm{D}}^{\prime}\right)$ due to ventilation-perfusion mismatching. A low $P_{\mathrm{aCO}}$ equilibrium point could be attributed to chronic respiratory alkalosis. Importantly, a lower ventilatory efficiency has been identified as a predictor of mortality for patients with cardiopulmonary disease including, but not limited to, COPD, pulmonary hypertension and chronic heart failure [10-12].

Given this guiding framework, the purpose of this narrative review is to summarise the physiological factors that may account for a higher $V^{\prime}{ }_{E} / V^{\prime} \mathrm{CO}_{2}$ during exercise with advancing age and in healthy pregnancy, both of which are progressive life stages.

\section{Normal ageing}

The respiratory system reaches maturity around 20-25 years, after which there is a progressive decline in pulmonary function [13]. Despite this regression, the respiratory system is capable of maintaining adequate pulmonary gas exchange throughout the lifespan in the absence of cardiopulmonary disease [13-15]. Significant structural changes to the lungs, airways, chest wall and respiratory muscles result in a lower ventilatory capacity in healthy individuals above the age of 60 years when compared to individuals aged 20-30 years [13] as demonstrated by the size and shape of their maximum expiratory flow-volume curves (figure 3) [16]. Accordingly, older individuals have a reduced ability to accommodate increases in ventilatory demand during exercise relative to their younger counterparts, and are subject to greater mechanical ventilatory constraints and associated exertional symptoms (i.e. dyspnoea) [17]. A more detailed summary of the implications of these age-related structural and functional changes to the respiratory system on the ventilatory response to exercise have been presented elsewhere [13].

Ventilatory efficiency is lower for any given work-rate during exercise [18, 19], and also when assessed as the $V^{\prime}{ }_{E} / V^{\prime} \mathrm{CO}_{2}$ slope $[6,8,20-25]$, the $V^{\prime}{ }_{E} / V_{\mathrm{CO}_{2} \mathrm{AT}}^{\prime}[6,19,23,26]$ or the $V^{\prime}{ }_{\mathrm{E}} / V^{\prime} \mathrm{CO}_{2}$ nadir [6] in healthy older compared to younger individuals. These observations are independent of cardiorespiratory fitness [27] and unrelated to oxygen saturation or metabolic acidosis [20, 21]. Lower ventilatory efficiency in 


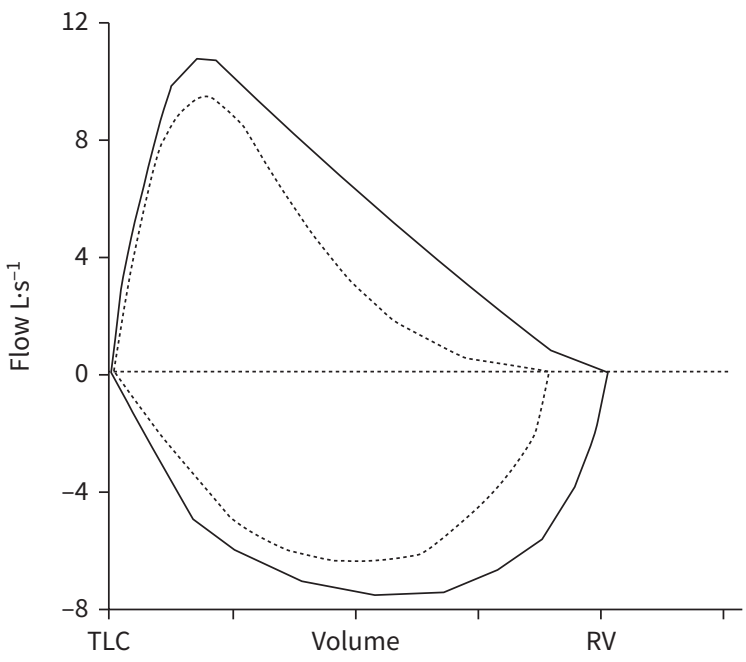

FIGURE 3 Changes in the maximal expiratory flow-volume curve with normal ageing. Curves from an older (dashed line) and a younger individual (solid line), expressed as a percentage of vital capacity. TLC: total lung capacity; RV: residual volume. Reproduced from [14] with permission from the publisher.

healthy older compared to younger individuals in the context of an isocapnic response to exercise supports the idea that the higher $V_{\mathrm{E}}^{\prime} / V^{\prime} \mathrm{CO}_{2}$ associated with normal ageing is a compensatory response to an increase in $V^{\prime}$ and not a lowering of the $P_{\mathrm{aCO}_{2}}$ equilibrium point [15, 20, 21, 28]. This is further supported by a widening of the difference in measured $P_{\mathrm{aCO}}$ and end-tidal $\mathrm{CO}_{2}$ tension $\left(P_{\mathrm{ETCO}}\right)$ in healthy older individuals compared to their younger counterparts [29].

There is a greater non-uniformity of $V_{\mathrm{A}}^{\prime}$ relative to perfusion $\left(V_{\mathrm{A}}^{\prime} / Q^{\prime}\right)$ in healthy older compared to younger individuals [30-34]. The resultant increase in physiological dead space is likely the most significant contributor to the higher $V^{\prime}{ }_{E} / V^{\prime} \mathrm{CO}_{2}$ response to exercise observed in the former. However, the precise mechanism(s) responsible for the progressive rise in $V_{A}^{\prime} / Q^{\prime}$ inequality with age remains equivocal. Age-related loss in elastic recoil of the lungs causes the sigmoidal pressure-volume relationship of the lungs to shift to the right (i.e. increased lung compliance) [35], which can lead to dynamic narrowing or closure of the airways at lower lung volumes, reduced maximal expiratory flows and alveolar gas trapping [13]. Nonetheless, evidence does not support a role of decreased closing volume in the aged-related increase in $V_{\mathrm{A}}^{\prime} / Q^{\prime}$ inequality [33]. The increase in diameter of the larger airways with normal ageing causes an $\sim 55 \%$ greater anatomical dead space, assuming a dead space volume of $150 \mathrm{~mL}$ in a healthy younger individual [34]. However, even though the $V_{\mathrm{D}} / V_{\mathrm{T}}$ has been shown to be elevated in older individuals ( $\geqslant 60$ years old) compared with younger individuals ( $\sim 30$ years old) by $15-20 \%$, abnormally high $V_{\mathrm{D}} / V_{\mathrm{T}}$ values are not observed [13]. The age-related increase in anatomical dead space is therefore unlikely to contribute meaningfully to the lower exercise ventilatory efficiency (higher $V_{\mathrm{E}}^{\prime} / V^{\prime} \mathrm{CO}_{2}$ response) in healthy older individuals compared with younger individuals [32]. Other potential contributors to an increased physiological dead space include the age-related losses in alveolar-capillary surface area [34] as well as pulmonary capillary blood volume [36]. In addition to an increased physiological dead space, we cannot discount potential age-related differences in neural, mechanical, or humoral stimuli in increasing $V^{\prime}{ }_{E} / V^{\prime} \mathrm{CO}_{2}$, which are known to stimulate $V_{\mathrm{E}}^{\prime}$ during exercise [20]. For example, there is evidence for factors linked to alterations in central motor-neuron drive [37, 38], regulation of muscle contraction as a result of fibre type shifts [39], and higher blood lactate concentrations [19] with advancing age. Importantly, despite the potential for greater ventilatory mechanical constraints and inefficiencies in gas exchange observed in healthy older individuals compared with younger individuals, the respiratory system nevertheless fulfils its primary role of eliminating $\mathrm{CO}_{2}$ and maintaining arterial oxygen saturation. Accordingly, the normal age-related decline in exercise ventilatory efficiency is generally not a primary cause of exercise limitation in older healthy individuals and is of little clinical significance [40].

The normal decline in exercise ventilatory efficiency with advancing age is more prominent in men than women [20, 24]. For example, Poulin et al. [20] showed that the slope of the $V_{E}^{\prime} / V^{\prime} \mathrm{CO}_{2}$ response to exercise rises at a rate of $1.23 \%$ versus $0.93 \%$ per year in healthy men and women, respectively. Whether 
this sex difference relates to a relatively larger increase in $V_{\mathrm{D}}^{\prime}$ or a lower $P_{\mathrm{aCO}}$ equilibrium point in men compared with women has not been determined [24]. Interestingly, despite a slower decline with age, women tend to have a slightly higher $V^{\prime}{ }_{E} / V^{\prime} \mathrm{CO}_{2} \mathrm{AT}$ compared to age-matched men [6, 23, 26, 41]. This higher $V^{\prime}{ }_{\mathrm{E}} / V^{\prime} \mathrm{CO}_{2} \mathrm{AT}$ in women was shown to be significantly associated with a lower $P_{\mathrm{ETCO}_{2}}$, rather than a more tachypnoeic breathing pattern [41]. Therefore, a relatively greater $V_{\mathrm{D}}^{\prime}$ in healthy women compared to men is an unlikely explanation. An alternative explanation is that leg strength is inversely related to $V^{\prime}{ }_{E} / V$ ' $\mathrm{CO}_{2} \mathrm{AT}$ in healthy older women but not in men during exercise, independent of age and cardiorespiratory fitness [41]. Gonzales et al. [41] therefore speculated that the lower muscular strength in women could result in a greater metabolic stress with attendant increased activation of group III and IV sensory afferents, which could stimulate a disproportionate increase in $V_{\mathrm{E}}^{\prime}$ relative to $V_{\mathrm{CO}_{2}}^{\prime}$, as has been shown in people with heart failure [42-44] or chronic obstructive pulmonary disease [45]. Additionally, $V^{\prime}{ }_{\mathrm{E}} / V^{\prime} \mathrm{CO}_{2}$ is elevated in the presence of expiratory flow limitation (EFL) at higher levels of $V_{E}^{\prime}$ during exercise [46], which reflects greater mechanical ventilatory constraints. Older individuals are more likely to develop EFL compared with younger individuals due to the loss of ventilatory capacity with normal ageing, and older women are more likely to develop EFL compared with older men due to relatively smaller lungs and disproportionately narrower airways [17]. Further research on the mechanisms of sex differences in ventilatory efficiency is warranted.

\section{Healthy pregnancy}

Human pregnancy is characterised by a series of well-orchestrated progressive adaptations to several integrated physiological systems (i.e. respiratory, cardiovascular, metabolic, renal and thermoregulatory) that are initiated and maintained by gestational hormones, which are almost fully established by the end of the first trimester and are critical to fetal growth and development [47]. The respiratory effects of human pregnancy are well documented [48-51], and include adaptations in static and dynamic pulmonary mechanics as well as increases in the drive to breathe both at rest and during exercise. In this section of our review, we focus specifically on the physiological determinants of the exaggerated $V^{\prime}{ }_{\mathrm{E}} / V^{\prime} \mathrm{CO}_{2}$ response to exercise in healthy human pregnancy uncomplicated by co-existing pathology (e.g. pulmonary hypertension, pre-eclampsia).

Compared with the non-pregnant control condition, both $V_{\mathrm{E}}^{\prime}$ and $V_{\mathrm{A}}^{\prime}$ are higher by $3-5 \mathrm{~L} \cdot \mathrm{min}^{-1}$ at rest during pregnancy [52-68]. Pregnancy-induced increases in $V_{\mathrm{E}}^{\prime}$ and $V_{\mathrm{A}}^{\prime}$ are proportionally greater than concomitant increases in $V_{\mathrm{CO}_{2}}^{\prime}[61,65]$. As a result, resting measures of $P_{\mathrm{aCO}}$ and cerebrospinal fluid $P_{\mathrm{CO}_{2}}$ $\left(P_{\mathrm{CSFCO}_{2}}\right)$ are reduced by 6-10 mmHg: from $\sim 38-40 \mathrm{mmHg}$ to $\sim 30-34 \mathrm{mmHg}$ for $P_{\mathrm{aCO}_{2}}$, and from $\sim 41-$ $47 \mathrm{mmHg}$ to $\sim 37-42 \mathrm{mmHg}$ for $P_{\mathrm{CSFCO}_{2}}$ [52, 54-57, 59, 62, 65, 68-71]. This maternal hyperventilation and attendant respiratory alkalosis are only partially compensated for by the kidneys via lowering of plasma and cerebrospinal fluid (CSF) bicarbonate concentrations such that arterial and CSF hydrogen ion concentrations are reduced by $2-5 \mathrm{nEq} \cdot \mathrm{L}^{-1}$ at rest $[52,54-57,59,60,65,68,70,71]$. According to more contemporary quantitative acid-base theory [72], pregnancy-induced reductions in arterial and CSF hydrogen ion concentrations reflect the alkalinising effect of reductions in $P_{\mathrm{aCO}_{2}}$ and $P_{\mathrm{CSFCO}_{2}}$, which are partially offset by the acidifying effect of reductions in plasma and CSF strong ion difference [54, 55, 57, $60,69,73]$, where the strong ion difference represents the concentration difference of strongly dissociated positive (e.g. sodium, potassium, calcium and magnesium) and negative ions (e.g. chloride and lactate) in solution.

A detailed description of the complex physiological mechanisms underlying maternal hyperventilation is beyond the scope of this review and has been presented elsewhere [47, 49, 73]. Briefly, evidence suggests that the hyperventilation and attendant hypocapnia/alkalosis of human pregnancy results from a complex interaction between alterations in acid-base balance (arterial and CSF) and several other factors that affect the control of breathing, including increased circulating levels of female sex steroid hormones (i.e. progesterone and oestrogen), decreased plasma osmolality, augmented circulating levels of angiotensin II and arginine vasopressin, increased non-chemoreflex (wakefulness) drives to breathe, increased central and peripheral chemoreflex sensitivity, increased $V^{\prime} \mathrm{CO}_{2}$, and decreased cerebral blood flow [52, 54, 55, 57, 69, 74-78].

JENSEN et al. [74] were the first to show that pregnancy-induced changes in arterial and CSF acid-base balance lowered the central chemoreflex's ventilatory recruitment threshold for $\mathrm{CO}_{2}\left(\mathrm{VRT}_{\mathrm{CO}_{2}}\right)$, which subsequently decreased the respiratory control system's resting $P_{\mathrm{aCO}}$ equilibrium point from $\sim 40 \mathrm{mmHg}$ whilst non-pregnant to $\sim 32 \mathrm{mmHg}$ in the third pregnancy trimester (figure 4). In moving forward, the influence of these changes in the $\mathrm{VRT}_{\mathrm{CO}_{2}}$ and $P_{\mathrm{aCO}_{2}}$ equilibrium point on the $V_{\mathrm{E}}^{\prime} / V^{\prime} \mathrm{CO}_{2}$ response to maternal exercise will be discussed. 


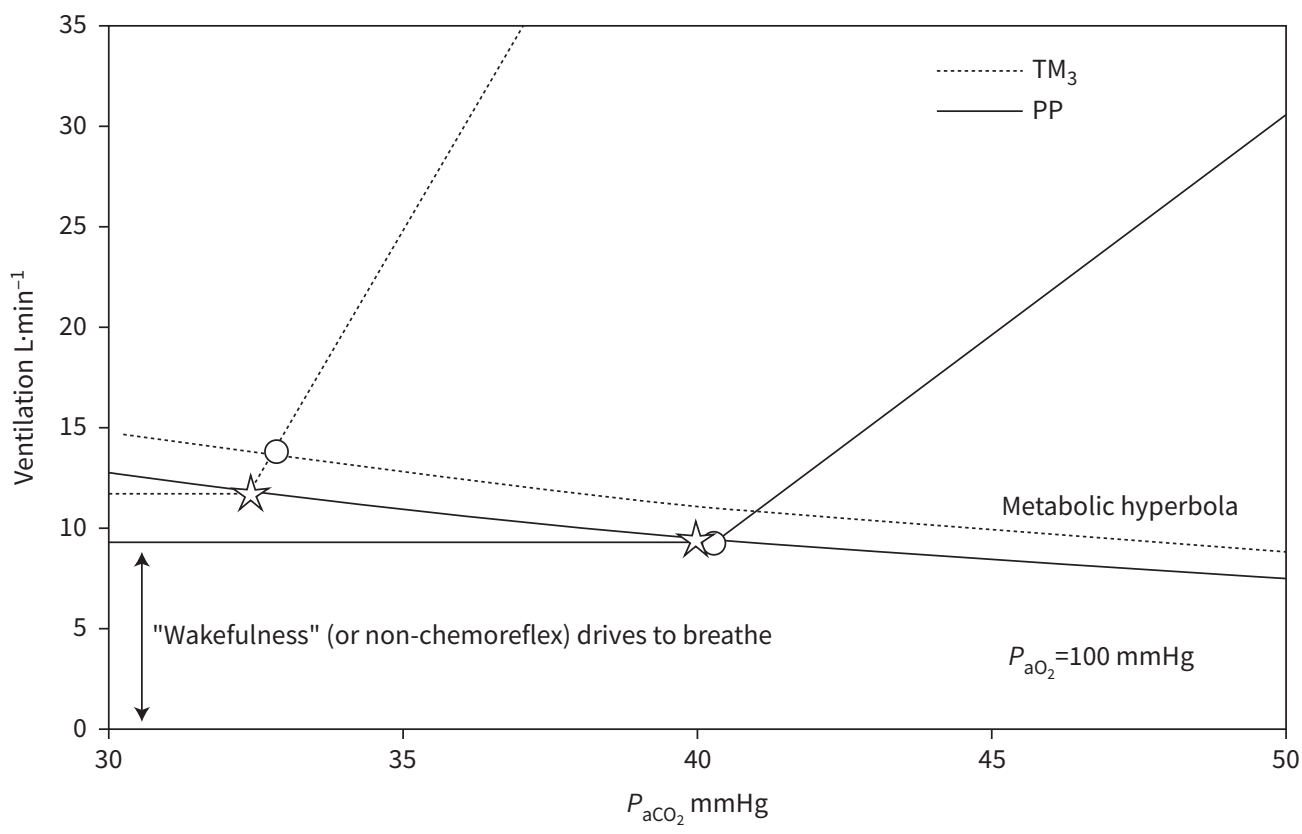

FIGURE 4 Physiological determinants of the pregnancy-induced decrease in the respiratory control systems' resting arterial carbon dioxide tension $\left(P_{\mathrm{acO}}\right)$ equilibrium point, where open circles and closed stars represent predicted and measured equilibrium point values, respectively, (i.e. intersection between minute ventilation$\mathrm{P}_{\mathrm{acO}}$, response curve and the metabolic hyperbola). Briefly, pregnancy-induced reductions in the respiratory control systems' resting $P_{\mathrm{acO}}$ equilibrium point are due primarily to reductions in the central chemoreflex ventilatory recruitment threshold for $\mathrm{CO}_{2}$ that occurs in conjunction with pregnancy-induced changes in arterial and cerebrospinal fluid acid-base balance. $\mathrm{TM}_{3}$ : third pregnancy trimester; PP: postpartum; $P_{\mathrm{aO}_{2}}$ : arterial oxygen tension. Reproduced from [74] with permission from the publisher.

There is universal agreement that the $V^{\prime}{ }_{\mathrm{E}} / V^{\prime} \mathrm{CO}_{2}$ response to both weight-bearing (e.g., treadmill walking) and weight-supported exercise (e.g. cycling) is elevated by as much as $\sim 30 \%$ in the pregnant compared to non-pregnant state (figure 5) [52-59, 61, 62, 65-67, 69, 79] and largely unaffected by aerobic conditioning $[64,66,79]$. Typical values of the $V_{\mathrm{E}}^{\prime} / V^{\prime} \mathrm{CO}_{2}$ slope during exercise in late pregnancy range from 31-34 compared to postpartum values of $\sim 26-28$ (figure 5) [52, 63], while typical $V_{\mathrm{E}}^{\prime} / V^{\prime} \mathrm{CO}_{2}$ values during exercise in late pregnancy compared to the non-pregnant control state range from: $\sim 32-36$ compared to $\sim 27-30$ at the ventilatory/anaerobic threshold [53, 63]; 28-41 versus $\sim 24-39$ at any standardised submaximal exercise intensity (figure 5) [54-59, 62, 65, 67, 69]; and 32-39 versus 26-34 at peak exercise (figure 5) $[53,56,58,59,61,63]$. As a consequence of the exaggerated $V_{\mathrm{E}}^{\prime} / V^{\prime} \mathrm{CO}_{2}$ response to exercise, both $P_{\mathrm{aCO}}$ and $P_{\mathrm{ETCO}_{2}}$ are $\sim 4-8 \mathrm{mmHg}$ lower during maternal exercise [52, 54-57, $60,62,69,79]$. However, neither pregnancy nor advancing gestation has an effect on the exercise-induced change in $P_{\mathrm{aCO}}$ or $P_{\mathrm{ETCO}}$ from rest [52, 55, 57, 69]. The collective results of controlled longitudinal studies suggest that pregnancy-induced increases in the $V^{\prime}{ }_{E} / V^{\prime} \mathrm{CO}_{2}$ response to exercise are evident by 7 weeks gestation and almost fully established by the end of the first trimester, with only modest progressive increases occurring thereafter in parallel with modest progressive decreases in the $P_{\mathrm{aCO}}$ equilibrium point and its major physiological determinants [54, 58, 61, 63, 66, 67, 79].

Mechanistically, the exaggerated $V^{\prime}{ }_{E} / V^{\prime} \mathrm{CO}_{2}$ response to exercise during pregnancy cannot be explained, in whole or in part, by concurrent pregnancy-induced increases in $V_{\mathrm{D}}^{\prime}$ [65]. For example, PIVARNIK et al. [65] calculated $V^{\prime}$ D from direct measures of $P_{\mathrm{aCO}}$ obtained via radial artery cannulation at rest and during both constant-load cycling (at 50 and 75 Watts) and treadmill walking exercise $\left(4.0 \mathrm{~km} \cdot \mathrm{h}^{-1}\right.$ at $2.5 \%$ and $12 \%$ grade) in seven healthy normal primigravid women studied late in the third trimester and again $\sim 3$ months postpartum. In that study, $V_{\mathrm{E}}^{\prime}, V_{\mathrm{A}}^{\prime}$ and $V_{\mathrm{E}}^{\prime} / V^{\prime} \mathrm{CO}_{2}$ were significantly increased at rest (by $\sim 4 \mathrm{~L} \cdot \mathrm{min}^{-1}$, $\sim 3 \mathrm{~L} \cdot \mathrm{min}^{-1}$ and $\sim 6$ units, respectively) and during exercise (by $\sim 8-13 \mathrm{~L} \cdot \mathrm{min}^{-1}, \sim 8-10 \mathrm{~L} \cdot \mathrm{min}^{-1}$ and $\sim 3$ 8 units, respectively) in late pregnancy compared to postpartum, despite no statistically significant effect of pregnancy status or exercise condition on $V_{\mathrm{D}}^{\prime}$. The notion that the exaggerated $V_{\mathrm{E}}^{\prime} / V_{\mathrm{CO}_{2}}^{\prime}$ response to exercise during pregnancy is not mechanistically linked to increased $V_{\mathrm{D}}^{\prime}$ is further supported, albeit 

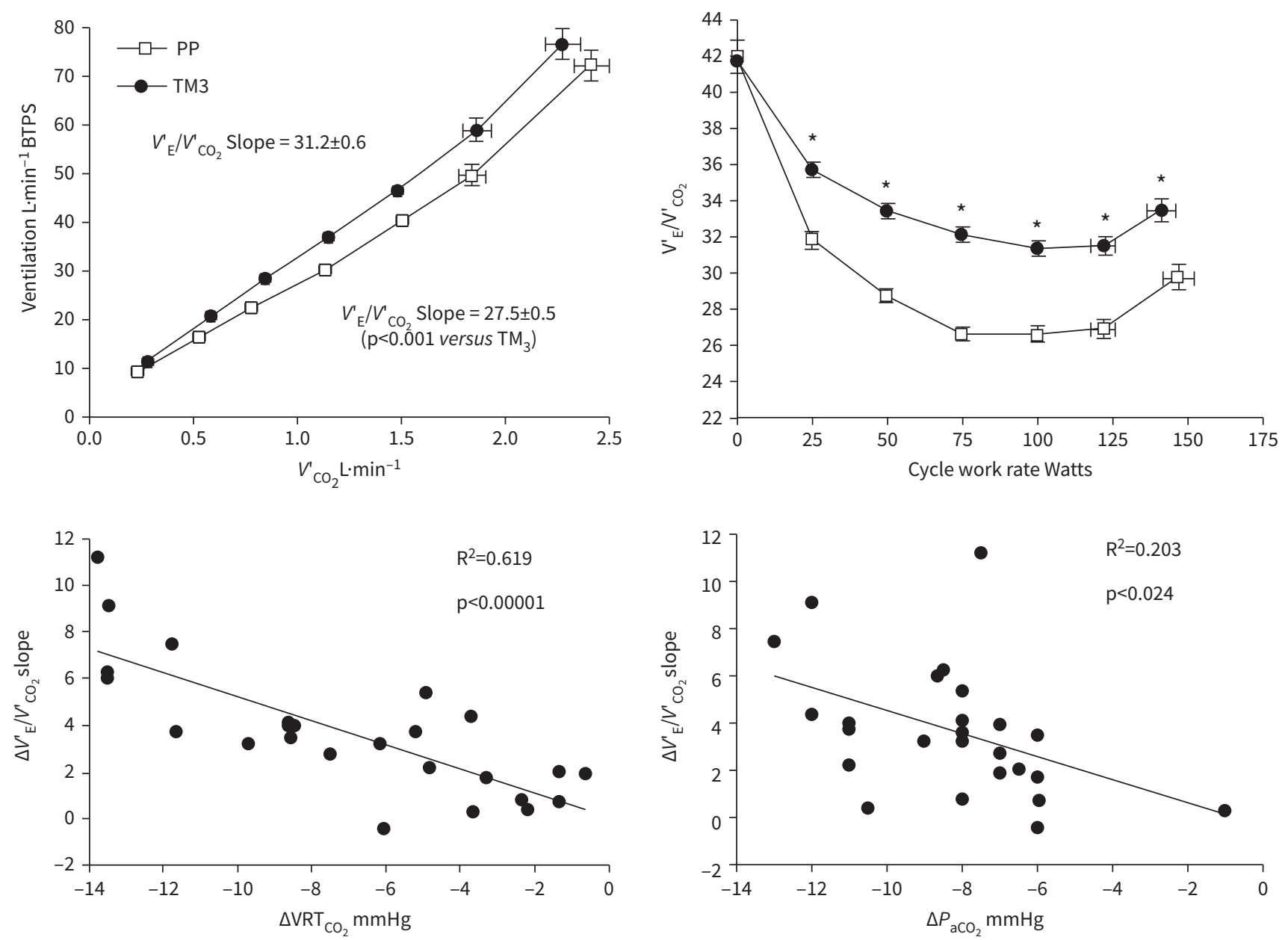

FIGURE 5 Effect of pregnancy on the ventilatory equivalent for carbon dioxide $\left(V_{E}^{\prime} / V^{\prime} \mathrm{CO}_{2}\right)$ response to symptom-limited incremental cycle exercise testing and physiological correlates of change in the exaggerated $V_{E}^{\prime} / V^{\prime}{ }_{\mathrm{CO}}$, response. Data points are mean \pm sEM at rest, at standardised submaximal power outputs during exercise, and at peak exercise. PP: postpartum; $\mathrm{TM}_{3}$ : third pregnancy trimester; $V^{\prime}{ }_{\mathrm{E}}$ : minute ventilation; $V^{\prime} \mathrm{CO}_{2}$ : carbon dioxide production; $\triangle$ : pregnancy-induced change ( $\mathrm{TM}_{3}$ minus $\mathrm{PP}$ ); $\mathrm{VRT}_{\mathrm{CO}_{2}}$ : ventilatory recruitment threshold for $\mathrm{CO}_{2} ; P_{\mathrm{aco}}$ : arterial carbon dioxide tension. ${ }^{*}: p<0.05$ versus PP. Adapted and modified from [52] with permission from the publisher.

indirectly, by an apparent lack of effect of pregnancy and advancing gestation on pulmonary diffusing capacity for carbon monoxide [56, 77, 80, 81].

In the setting of an unchanged $V^{\prime}{ }_{D}$ during maternal exercise, the modified alveolar ventilation equation predicts that pregnancy-induced changes in the respiratory control systems' $P_{\mathrm{aCO}}$ equilibrium point (and its physiological determinants) are most likely responsible for the increased $V^{\prime}{ }_{E} / V^{\prime} \mathrm{CO}_{2}$ response to exercise during pregnancy. Indeed, a study of 25 healthy women found that the magnitude of the pregnancy-induced increase in the $V_{E}^{\prime} / V^{\prime} \mathrm{CO}_{2}$ response to exercise was inversely related to the magnitude of fall in the $\mathrm{VRT}_{\mathrm{CO}_{2}}$ and, by extension, the respiratory control systems' $P_{\mathrm{aCO}_{2}}$ equilibrium point [52] (figure 5).

By all accounts, an exaggerated $V^{\prime}{ }_{E} / V^{\prime} \mathrm{CO}_{2}$ response to exercise is a normal physiological adaptation that accompanies healthy human pregnancy and that is of little clinical significance. However, to our knowledge, no study has examined the impact of comorbid conditions on the $V_{\mathrm{E}}^{\prime} / V^{\prime} \mathrm{CO}_{2}$ response to maternal exercise and whether pathophysiological increases in the $V^{\prime}{ }_{E} / V^{\prime} \mathrm{CO}_{2}$ response to exercise above and beyond those expected in a normal pregnancy predict adverse maternal and/or fetal health outcomes. It is certainly reasonable to assume that any comorbid condition that has an adverse effect on cardiac, pulmonary and/or circulatory function (e.g. pulmonary arterial hypertension, heart failure, cystic fibrosis, interstitial lung disease, chronic kidney disease) would be associated with an abnormally high $V_{\mathrm{E}}^{\prime} / V^{\prime} \mathrm{CO}_{2}$ response to maternal exercise. Further research is needed in this regard. Moreover, we are unaware of 
studies that have examined the potential use of cardiopulmonary exercise testing with measurement of $V^{\prime}{ }_{E} / V^{\prime} \mathrm{CO}_{2}$ for early detection and diagnosis of potentially adverse pregnancy-induced adaptions in cardiac, pulmonary and/or circulatory function. Again, it is reasonable to hypothesise that a $V_{\mathrm{E}}^{\prime} / V^{\prime} \mathrm{CO}_{2}$ response to exercise above and beyond that expected for an otherwise healthy pregnant woman might help identify the existence of pregnancy related cardiopulmonary complication(s), especially those that might increase $V_{\mathrm{E}}^{\prime} / V^{\prime} \mathrm{CO}_{2}$ by increasing $V_{\mathrm{D}} / V_{\mathrm{T}}$ (e.g. abnormally high pulmonary vascular resistance due to pulmonary hypertension, abnormally low cardiac output due left ventricular dysfunction) in the setting of a $P_{\mathrm{aCO}_{2}}$ that is within the normal expected range.

\section{Conclusion}

The ventilatory equivalent for $\mathrm{CO}_{2}\left(V_{\mathrm{E}}^{\prime} / V_{\mathrm{CO}_{2}}^{\prime}\right)$ is an index of ventilatory efficiency that is determined by changes in $V_{\mathrm{D}}$ and/or $P_{\mathrm{aCO}}$. While the $V_{\mathrm{E}}^{\prime} / V_{\mathrm{CO}_{2}}^{\prime}$ response to exercise is higher with normal ageing and during healthy pregnancy, these are anticipated consequences of age-related increases in $V_{\mathrm{D}}$ and pregnancy-related decreases in the $P_{\mathrm{aCO}}$ equilibrium point. Importantly, the resultant increase in $V_{\mathrm{E}}^{\prime} / V^{\prime} \mathrm{CO}_{2}$ during exercise is not in the pathological range (i.e. identified as being associated with increased risk of adverse health outcomes, including premature death), and on average, is well below the critical threshold identified for prognostic indication in cardiopulmonary disease.

Provenance: Commissioned article, peer reviewed.

Previous articles in this series: No. 1: Laveneziana P, Di Paolo M, Palange P. The clinical value of cardiopulmonary exercise testing in the modern era. Eur Respir Rev 2021; 30: 200187. No. 2: Agnostoni P, Sciomer S, Palermo P, et al. Minute ventilation/carbon dioxide production in chronic heart failure. Eur Respir Rev 2021; 30: 200141. No. 3: Watson M, Ionescu MF, Sylvester K, et al. Minute ventilation/carbon dioxide production in patients with dysfunctional breathing. Eur Respir Rev 2021; 30: 200182. No. 4: Ward SA. Ventilation/carbon dioxide output relationships during exercise in health. Eur Respir Rev 2021; 30: 200160. No. 5: Collins SÉ, Phillips DB, Brotto AR, et al. Ventilatory efficiency in athletes, asthma and obesity. Eur Respir Rev 2021; 30: 200206.

Conflict of interest: None declared.

Support statement: M.R. Schaeffer was supported by a fellowship from the Michael Smith Foundation for Health Research. J.A. Guenette was supported by Clinical Rehabilitation New Investigator Award from the Canadian Institutes of Health Research and a Scholar award from the Michael Smith Foundation for Health Research. D. Jensen holds a Canada Research Chair, Tier II, in Clinical Exercise \& Respiratory Physiology from the Canadian Institutes of Health Research. The funders had no role in the preparation of this correspondence.

\section{References}

1 Cooper DM, Kaplan MR, Baumgarten L, et al. Coupling of ventilation and $\mathrm{CO}_{2}$ production during exercise in children. Pediatr Res 1987; 21: 568-572.

2 Forster HV, Pan LG. Breathing during exercise: demands, regulation, limitations. Adv Exp Med Biol 1988; 227: 257-276.

3 Duffin J. The chemoreflex control of breathing and its measurement. Can J Anaesth 1990; 37: 933-942.

4 Duffin J. Role of acid-base balance in the chemoreflex control of breathing. J Appl Physiol 2005; 99: 2255-2265.

5 Duffin J, Mohan RM, Vasiliou P, et al. A model of the chemoreflex control of breathing in humans: model parameters measurement. Respir Physiol 2000; 120: 13-26.

6 Sun XG, Hansen JE, Garatachea N, et al. Ventilatory efficiency during exercise in healthy subjects. Am J Respir Crit Care Med 2002; 166: 1443-1448.

7 ATS/ACCP statement on cardiopulmonary exercise testing. Am J Resp Crit Care 2003; 167: 211-277.

8 McConnell AK, Davies CT. A comparison of the ventilatory responses to exercise of elderly and younger humans. J Gerontol 1992; 47: B137-B141.

9 Stickland MK, Butcher SJ, Marciniuk DD, et al. Assessing exercise limitation using cardiopulmonary exercise testing. Pulm Med 2012; 2012: 824091.

10 Neder JA, Alharbi A, Berton DC, et al. Exercise ventilatory inefficiency adds to lung function in predicting mortality in COPD. COPD 2016; 13: 416-424.

11 Wensel R, Francis DP, Meyer FJ, et al. Incremental prognostic value of cardiopulmonary exercise testing and resting haemodynamics in pulmonary arterial hypertension. Int J Cardiol 2013; 167: 1193-1198.

12 Chua TP, Ponikowski P, Harrington D, et al. Clinical correlates and prognostic significance of the ventilatory response to exercise in chronic heart failure. J Am Coll Cardiol 1997; 29: 1585-1590. 
13 Johnson BD, Dempsey JA. Demand vs. capacity in the aging pulmonary system. Exerc Sport Sci Rev 1991; 19: 171-210.

14 Janssens JP. Aging of the respiratory system: impact on pulmonary function tests and adaptation to exertion. Clin Chest Med 2005; 26: 469-484.

15 Roman MA, Rossiter HB, Casaburi R. Exercise, ageing and the lung. Eur Respir J 2016; 48: 1471-1486.

16 Fowler RW, Pluck RA, Hetzel MR. Maximal expiratory flow-volume curves in Londoners aged 60 years and over. Thorax 1987; 42: 173-182.

17 Molgat-Seon Y, Dominelli PB, Ramsook AH, et al. The effects of age and sex on mechanical ventilatory constraint and dyspnea during exercise in healthy humans. J Appl Physiol 2018; 124: 1092-1106.

18 Faisal A, Webb KA, Guenette JA, et al. Effect of age-related ventilatory inefficiency on respiratory sensation during exercise. Respir Physiol Neurobiol 2015; 205: 129-139.

19 Prioux J, Ramonatxo M, Hayot M, et al. Effect of ageing on the ventilatory response and lactate kinetics during incremental exercise in man. Eur J Appl Physiol 2000; 81: 100-107.

20 Poulin MJ, Cunningham DA, Paterson DH, et al. Ventilatory response to exercise in men and women 55 to 86 years of age. Am J Respir Crit Care Med 1994; 149: 408-415.

21 Brischetto MJ, Millman RP, Peterson DD, et al. Effect of aging on ventilatory response to exercise and $\mathrm{CO}_{2}$. J Appl Physiol Respir Environ Exerc Physiol 1984; 56: 1143-1150.

22 Habedank D, Reindl I, Vietzke G, et al. Ventilatory efficiency and exercise tolerance in 101 healthy volunteers. Eur J Appl Physiol Occup Physiol 1998; 77: 421-426.

23 Ofir D, Laveneziana P, Webb KA, et al. Sex differences in the perceived intensity of breathlessness during exercise with advancing age. J Appl Physiol 2008; 104: 1583-1593.

24 Neder JA, Nery LE, Peres C, et al. Reference values for dynamic responses to incremental cycle ergometry in males and females aged 20 to 80. Am J Respir Crit Care Med 2001; 164: 1481-1486.

25 Ebine N, Ahad-Abdulkarim DA, Miyake Y, et al. Influence of age on cardiorespiratory kinetics during sinusoidal walking in humans. Front Physiol 2018; 9: 1191.

26 Loe H, Steinshamn S, Wisloff U. Cardio-respiratory reference data in 4631 healthy men and women 20-90 years: the HUNT 3 fitness study. PLoS One 2014; 9: e113884.

27 Yerg JE 2nd, Seals DR, Hagberg JM, et al. Effect of endurance exercise training on ventilatory function in older individuals. J Appl Physiol 1985; 58: 791-794.

28 Mummery HJ, Stolp BW, de LDG, et al. Effects of age and exercise on physiological dead space during simulated dives at 2.8 ATA. J Appl Physiol 2003; 94: 507-517.

29 Janssens JP, Pache JC, Nicod LP. Physiological changes in respiratory function associated with ageing. Eur Respir J 1999; 13: 197-205.

30 Wagner PD, Laravuso RB, Uhl RR, et al. Continuous distributions of ventilation-perfusion ratios in normal subjects breathing air and 100 per cent $\mathrm{O}_{2}$. J Clin Invest 1974; 54: 54-68.

31 Thurlbeck WM, Angus GE. Growth and aging of the normal human lung. Chest 1975; 67: 2 Suppl, 3S-6S.

32 Raine JM, Bishop JM. A-a difference in $\mathrm{O}_{2}$ tension and physiological dead space in normal man. J Appl Physiol 1963; 18: 284-288.

33 Cardus J, Burgos F, Diaz O, et al. Increase in pulmonary ventilation-perfusion inequality with age in healthy individuals. Am J Respir Crit Care Med 1997; 156: 648-653.

34 Tenney SM, Miller RM. Dead space ventilation in old age. J Appl Physiol 1956; 9: 321-327.

35 Turner JM, Mead J, Wohl ME. Elasticity of human lungs in relation to age. J Appl Physiol 1968; 25: 664-671.

36 Crapo RO, Morris AH, Gardner RM. Reference values for pulmonary tissue volume, membrane diffusing capacity, and pulmonary capillary blood volume. Bull Eur Physiopathol Respir 1982; 18: 893-899.

37 Kamen G, Knight CA. Training-related adaptations in motor unit discharge rate in young and older adults. J Gerontol A Biol Sci Med Sci 2004; 59: 1334-1338.

38 Kamen G, Sison SV, Du CC, et al. Motor unit discharge behavior in older adults during maximal-effort contractions. J Appl Physiol 1995; 79: 1908-1913.

39 Yu F, Hedstrom M, Cristea A, et al. Effects of ageing and gender on contractile properties in human skeletal muscle and single fibres. Acta Physiol 2007; 190: 229-241.

40 Phillips D, Collins S, Stickland M. Measurement and interpretation of exercise ventilatory efficiency. Front Physiol 2020; 11: 656.

41 Gonzales JU, Tucker SH, Kalasky MJ, et al. Leg strength is associated with ventilatory efficiency in older women. Int J Sports Med 2012; 33: 537-542.

42 Piepoli M, Clark AL, Volterrani M, et al. Contribution of muscle afferents to the hemodynamic, autonomic, and ventilatory responses to exercise in patients with chronic heart failure: effects of physical training. Circulation 1996; 93: 940-952.

43 Olson TP, Joyner MJ, Eisenach JH, et al. Influence of locomotor muscle afferent inhibition on the ventilatory response to exercise in heart failure. Exp Physiol 2014; 99: 414-426.

44 Keller-Ross ML, Johnson BD, Carter RE, et al. Improved ventilatory efficiency with locomotor muscle afferent inhibition is strongly associated with leg composition in heart failure. Int J Cardiol 2016; 202: 159-166. 
45 Gagnon P, Bussieres JS, Ribeiro F, et al. Influences of spinal anesthesia on exercise tolerance in patients with chronic obstructive pulmonary disease. Am J Respir Crit Care Med 2012; 186: 606-615.

46 Deruelle F, Nourry C, Mucci P, et al. Difference in breathing strategies during exercise between trained elderly men and women. Scand J Med Sci Sports 2008; 18: 213-220.

47 Weissgerber TL, Wolfe LA. Physiological adaptation in early human pregnancy: adaptation to balance maternal-fetal demands. Appl Physiol Nutr Metab 2006; 31: 1-11.

48 Hegewald MJ, Crapo RO. Respiratory physiology in pregnancy. Clin Chest Med 2011; 32: 1-13.

49 Jensen D, Webb KA, O'Donnell DE. Chemical and mechanical adaptations of the respiratory system at rest and during exercise in human pregnancy. Appl Physiol Nutr Metab 2007; 32: 1239-1250.

50 Jensen D, Ofir D, O.Donnell DE. Effects of pregnancy, obesity and aging on the intensity of perceived breathlessness during exercise in healthy humans. Respir Physiol Neurobiol 2009; 167: 87-100.

51 Jensen D, O'Donnell DE. Pregnancy/Obesity. In: Mahler DA, O'Donnell DE, eds. Dyspnea: Mechanisms, Measurement, and Management. Boca Raton, FL, CRC Press, 2014; pp. 39-54.

52 Jensen D, Webb KA, O'Donnell DE. The increased ventilatory response to exercise in pregnancy reflects alterations in the respiratory control systems ventilatory recruitment threshold for $\mathrm{CO}_{2}$. Respir Physiol Neurobiol 2010; 171: 75-82.

53 Davenport MH, Steinback CD, Mottola MF. Impact of pregnancy and obesity on cardiorespiratory responses during weight-bearing exercise. Respir Physiol Neurobiol 2009; 167: 341-347.

54 Weissgerber TL, Wolfe LA, Hopkins WG, et al. Serial respiratory adaptations and an alternate hypothesis of respiratory control in human pregnancy. Respir Physiol Neurobiol 2006; 153: 39-53.

55 Heenan AP, Wolfe LA. Plasma acid-base regulation above and below ventilatory threshold in late gestation. J Appl Physiol 2000; 88: 149-157.

56 Jensen D, Webb KA, Davies GA, et al. Mechanical ventilatory constraints during incremental cycle exercise in human pregnancy: implications for respiratory sensation. J Physiol 2008; 586: 4735-4750.

57 Charlesworth SA, Wolfe LA, Davies GA. Physicochemical analysis of acid-base responses to prolonged moderate exercise in late gestation. Appl Physiol Nutr Metab 2006; 31: 744-752.

58 Jensen D, Webb KA, Wolfe LA, et al. Effects of human pregnancy and advancing gestation on respiratory discomfort during exercise. Respir Physiol Neurobiol 2007; 156: 85-93.

59 Jensen D, Webb KA, Davies GA, et al. Mechanisms of activity-related breathlessness in healthy human pregnancy. Eur J Appl Physiol 2009; 106: 253-265.

60 Kemp JG, Greer FA, Wolfe LA. Acid-base regulation after maximal exercise testing in late gestation. $J$ Appl Physiol 1997; 83: 644-651.

61 Lotgering FK, van Doorn MB, Struijk PC, et al. Maximal aerobic exercise in pregnant women: heart rate, $\mathrm{O}_{2}$ consumption, $\mathrm{CO}_{2}$ production, and ventilation. J Appl Physiol 1991; 70: 1016-1023.

62 Heenan AP, Wolfe LA, Davies GA. Maximal exercise testing in late gestation: maternal responses. Obstet Gynecol 2001; 97: 127-134.

63 Lotgering FK, Struijk PC, van Doorn MB, et al. Anaerobic threshold and respiratory compensation in pregnant women. J Appl Physiol 1995; 78: 1772-1777.

64 McAuley SE, Jensen D, McGrath MJ, et al. Effects of human pregnancy and aerobic conditioning on alveolar gas exchange during exercise. Can J Physiol Pharmacol 2005; 83: 625-633.

65 Pivarnik JM, Lee W, Spillman T, et al. Maternal respiration and blood gases during aerobic exercise performed at moderate altitude. Med Sci Sports Exerc 1992; 24: 868-872.

66 Wolfe LA, Walker RM, Bonen A, et al. Effects of pregnancy and chronic exercise on respiratory responses to graded exercise. J Appl Physiol 1994; 76: 1928-1936.

67 Pivarnik JM, Ayres NA, Mauer MB, et al. Effects of maternal aerobic fitness on cardiorespiratory responses to exercise. Med Sci Sports Exerc 1993; 25: 993-998.

68 Templeton $A$, Kelman GR. Maternal blood-gases $\left(\mathrm{P}_{\mathrm{A}} \mathrm{O}_{2}-\mathrm{P}_{\mathrm{a}} \mathrm{O}_{2}\right)$, hysiological shunt and VD/VT in normal pregnancy. Br J Anaesth 1976; 48: 1001-1004.

69 Heenan AP, Wolfe LA. Plasma osmolality and the strong ion difference predict respiratory adaptations in pregnant and nonpregnant women. Can J Physiol Pharmacol 2003; 81: 839-847.

70 Hirabayashi $\mathrm{Y}$, Shimizu R, Saitoh K, et al. Acid-base state of cerebrospinal fluid during pregnancy and its effect on spread of spinal anaesthesia. Br J Anaesth 1996; 77: 352-355.

71 Machida H. Influence of progesterone on arterial blood and CSF acid-base balance in women. J Appl Physiol Respir Environ Exerc Physiol 1981; 51: 1433-1436.

72 Stewart PA. Modern quantitative acid-base chemistry. Can J Physiol Pharmacol 1983; 61: 1444-1461.

73 Wolfe LA, Kemp JG, Heenan AP, et al. Acid-base regulation and control of ventilation in human pregnancy. Can J Physiol Pharmacol 1998; 76: 815-827.

74 Jensen D, Duffin J, Lam YM, et al. Physiological mechanisms of hyperventilation during human pregnancy. Respir Physiol Neurobiol 2008; 161: 76-86.

75 Moore LG, Brodeur P, Chumbe O, et al. Maternal hypoxic ventilatory response, ventilation, and infant birth weight at 4,300 m. J Appl Physiol 1986; 60: 1401-1406. 
76 Moore LG, McCullough RE, Weil JV. Increased HVR in pregnancy: relationship to hormonal and metabolic changes. J Appl Physiol 1987; 62: 158-163.

77 Garcia-Rio F, Pino JM, Gomez L, et al. Regulation of breathing and perception of dyspnea in healthy pregnant women. Chest 1996; 110: 446-453.

78 Jensen D, Wolfe LA, Slatkovska L, et al. Effects of human pregnancy on the ventilatory chemoreflex response to carbon dioxide. Am J Physiol Regul Integr Comp Physiol 2005; 288: R1369-R1375.

79 Ohtake PJ, Wolfe LA. Physical conditioning attenuates respiratory responses to steady-state exercise in late gestation. Med Sci Sports Exerc 1998; 30: 17-27.

80 McAuliffe F, Kametas N, Rafferty GF, et al. Pulmonary diffusing capacity in pregnancy at sea level and at high altitude. Respir Physiol Neurobiol 2003; 134: 85-92.

81 McAuliffe F, Kametas N, Costello J, et al. Respiratory function in singleton and twin pregnancy. BJOG 2002; 109: 765-769.

82 Wasserman K, Whipp BJ. Exercise physiology in health and disease. Am Rev Respir Dis 1975; 112: 219-249. 